\title{
Activity and mechanism of flavokawain A in inhibiting P-glycoprotein expression in paclitaxel resistance of lung cancer
}

\author{
JUAN LI ${ }^{1}$, LEI ZHENG ${ }^{2}$, MI YAN ${ }^{1}$, JING WU ${ }^{1}$, YONGQING LIU ${ }^{1}$, XIAONA TIAN $^{1}$, \\ WEN JIANG ${ }^{3}$, LU ZHANG $^{3}$ and RONGMEI WANG ${ }^{1}$ \\ ${ }^{1}$ Department of Clinical Pharmacy, The Second Hospital of Shandong University, Jinan, Shandong 250033; \\ ${ }^{2}$ Department of Pharmacy, Shandong Provincial Third Hospital, Jinan, Shandong 250031; ${ }^{3}$ Central Research Laboratory, \\ The Second Hospital of Shandong University, Jinan, Shandong 250033, P.R. China
}

Received April 10, 2019; Accepted September 11, 2019

DOI: $10.3892 / \mathrm{ol} .2019 .11069$

\begin{abstract}
Lung cancer is one of the most common cancers, which is the leading cause of cancer-related death among various cancers worldwide. Flavokawain A (FKA), a chalcone found in the kava plant, exerts potent anticancer activity. However, the activity and mechanisms of FKA in inhibiting the viability of paclitaxel (PTX)-resistant lung cancer A549 (A549/T) have not been investigated. In the present study, the effect of FKA on the viability of A549/T and hepatotoxicity in normal liver epithelial cells was detected by Cell Counting Kit-8 assay. Flow cytometry, western blot analysis and Annexin V-FITC/PI apoptosis detection kit were used to assess cell apoptosis. The effect of FKA on permeability-glycoprotein (P-gp) expression was measured by reverse transcription-PCR and western blot analysis. The results indicated that FKA dose-dependently inhibited cell proliferation and induced cell apoptosis in PTX-resistant A549/T cells, with an $\mathrm{IC}_{50}$ value of $\sim 21 \mu \mathrm{M}$, while the $\mathrm{IC}_{50}$ value of $\mathrm{A} 549 / \mathrm{T}$ cells to PTX was $34.64 \mu \mathrm{M}$. FKA had no hepatic toxicity in liver epithelial cells. P-gp, which contributes to the chemoresistant phenotype, was not expressed in A549 cells but was remarkably enhanced in A549/T cells. FKA $(30 \mu \mathrm{M})$ decreased P-gp protein expression at 24 h by 3 -fold. Furthermore, FKA downregulated P-gp expression by blocking the PI3K/Akt pathway. These findings suggest FKA as a potential candidate for the treatment of PTX-resistant lung cancer.
\end{abstract}

Correspondence to: Dr Juan Li or Dr Rongmei Wang, Department of Clinical Pharmacy, The Second Hospital of Shandong University, 247 Beiyuan Road, Jinan, Shandong 250033, P.R. China

E-mail: 1ijuan198407@163.com

E-mail: rongmeiwang@hotmail.com

Key words: flavokawain A, chemotherapy resistance, permeabilityglycoprotein, PI3K/Akt signaling pathway

\section{Introduction}

Lung cancer is recognized as a leading cause of cancer-associated mortality and morbidity worldwide. According to the latest report of the American Cancer Society, 2.09 million new cases of lung cancer and $\sim 1.76$ million associated deaths were reported in the world in 2018 (1). For patients with lung cancer who cannot undergo surgery and radiotherapy, chemotherapy is still the major treatment option. However, chemotherapy only offers a modest survival advantage due to chemoresistance.

One of the molecular mechanisms that drive the development of chemoresistance is permeability-glycoprotein (P-gp)-mediated drug resistance (2). P-gp is often highly expressed in drug-resistant tumor cells. Several hydrophobic antitumor drugs, such as paclitaxel (PTX) and vinblastine, are subject to efflux out of the cells by P-gp (3). Therefore, the inhibition of P-gp-mediated drug efflux will presumably resensitize resistant cancer cells to chemotherapy drugs, which may lead to favorable chemotherapeutic outcomes. Various P-gp inhibitors, such as verapamil and cyclosporine, have been identified to reverse chemoresistance and sensitize tumor cells to chemotherapeutic agents (4). However, the clinical use of first-generation reversal agents (verapamil and cyclosporine) and second-generation inhibitors (dexverapamil and PSC-833) failed, due to undesired side effects and toxicity issues (5). Thus, no P-gp inhibitor has yet been applied for clinical use.

Natural compounds have great potential in inhibiting tumor growth and reversing chemotherapy resistance $(6,7)$. Chalcones are the most common group of flavonoid/isoflavonoid compounds found in vegetables and fruits. Earlier studies have demonstrated that numerous chalcones and their derivatives exhibit antitumor potential (8-10) with almost no toxic side effects to normal cells (11). Flavokawain A (FKA), a novel chalcone from the kava plant, induced apoptosis and $\mathrm{G}_{2} / \mathrm{M}$ arrest in different tumor cells (12-14). However, the potential therapeutic effect and the underlying molecular mechanism of FKA in paclitaxel (PTX)-resistant A549 cells are yet to be elucidated. 
In the present study, the PTX-resistant cell line A549/T was established. The efficacy of FKA in the inhibition of A549/T cell viability in vitro was assessed. Additionally, the capacity of FKA in reversing P-gp-mediated PTX resistance and the potential underlying mechanisms were also investigated.

\section{Materials and methods}

Reagents. FKA of $\geq 99 \%$ purity was purchased from Sigma-Aldrich (Merck KGaA). FKA was dissolved in dimethyl sulfoxide (DMSO) to form a $30 \mathrm{mM}$ stock solution. Cell Counting Kit-8 was purchased from Dojindo Molecular Technologies, Inc. PTX, LY294002 and DAPI were all obtained from Sigma-Aldrich (Merck KGaA). Insulin-like factor-1 (IGF-1) was purchased from Abcam (cat. no. 128524). Monoclonal rabbit anti-human P-gp (cat. no. 13342), monoclonal rabbit anti-human Akt (cat. no. 4691), polyclonal rabbit anti-human phosphorylated (p)-Akt (Ser 473; cat. no. 9271), monoclonal rabbit anti-human PARP (46D11; cat. no. 9532) and polyclonal rabbit anti-human $\beta$-actin (cat. no. 4970) were obtained from Cell Signaling Technology, Inc. The monoclonal mouse anti-human GAPDH antibody (cat. no. 60004-1-Ig) was obtained from ProteinTech Group, Inc. Horseradish peroxidase (HRP)-labelled goat anti-rabbit immunoglobulin G (cat. no. TA130023) and HRP-labelled goat anti-mouse immunoglobulin G (cat. no. TA130003) were obtained from OriGene Technologies, Inc.

Cell culture. Human lung adenocarcinoma cells A549 and PTX-resistant A549 (A549/T) cells were kindly gifted by the Central Research Laboratory of the Second Hospital of Shandong University (Jinan, China). Human hepatic epithelial cells THLE-3 were purchased from The Cell Bank of Type Culture Collection of the Chinese Academy of Sciences. All cells were cultured in RPMI-1640 (HyClone; GE Healthcare Life Sciences) containing $10 \%$ (v/v) fetal bovine serum (Gibco; Thermo Fisher Scientific, Inc.), penicillin-streptomycin $(100 \mathrm{U} / \mathrm{ml})$ and $2 \mathrm{mM}$ glutamine. The cells were cultured at $37^{\circ} \mathrm{C}$ in an incubator with $5 \% \mathrm{CO}_{2}$. The A549/T cells were maintained in medium with $3 \mathrm{nM}$ PTX to maintain PTX resistance in this cell line. Before the experiment, cells were cultured in drug-free medium for $\geq 2$ weeks.

Cell viability assay. The effect of PTX or FKA on the viability of A549 and A549/T cells was evaluated by Cell Counting Kit- 8 assay. The toxicity effect of FKA was also evaluated in human hepatic epithelial THLE-3 cells. A549, A549/T and THLE-3 cells were cultured in 96 -well plates $\left(4 \times 10^{3}\right.$ cells/well) and incubated overnight. Subsequently, the cells were stimulated for $48 \mathrm{~h}$ with increasing concentrations of PTX or FKA. The controls were treated with equal volume of DMSO. Cell proliferation inhibition was assayed by the Cell Counting Kit- 8 assay (CCK-8; Dojindo Molecular Technologies, Inc.) and the methods used were performed according to manufacturer's protocol. The absorbance was measured at $450 \mathrm{~nm}$ using a microplate reader.

Cell apoptosis assay. Cells were plated at a density of $2 \times 10^{5}$ cells $/ 2 \mathrm{ml}$ medium on 6 -well plates for $24 \mathrm{~h}$. Following treatment with various concentrations of FKA $(0,5,10$ and
$30 \mu \mathrm{M}$ ) for $24 \mathrm{~h}$, cell apoptosis was detected using DAPI staining. Cells were fixed with $90 \%$ ethanol $/ 5 \%$ acetic acid for $1 \mathrm{~h}$ at room temperature. Following 2 washes with PBS, cells were incubated with DAPI solution $(1.5 \mathrm{mg} / \mathrm{ml}$ in PBS) for $30 \mathrm{~min}$ at room temperature. Images of DAPI fluorescence were captured using a fluorescence microscope (magnification, x 200; Nikon Corporation). After treated by different concentrations of FKA $(0,5,10$ and $30 \mu \mathrm{M})$ for $24 \mathrm{~h}$ at $37^{\circ} \mathrm{C}$, cells were digested with trypsin and centrifuged at $120 \mathrm{x} \mathrm{g}$ for 5 min at $4^{\circ} \mathrm{C}$. Following 2 washes with PBS, levels of apoptosis were analyzed using an Annexin V-fluorescein isothiocyanate/propidium iodide apoptosis detection kit (BD Biosciences), according to the manufacturer's protocol. Quantification of fluorescence was determined using flow cytometry (FACSCalibur ${ }^{\mathrm{TM}}$; BD Biosciences), and the data were analyzed using WinMDI software v2.8 (Purdue University Cytometry Laboratories).

Reverse transcription-semi quantitative PCR (RT-PCR). Cells were treated with 0,3 and $30 \mu \mathrm{M}$ FKA for $24 \mathrm{~h}$ at $37^{\circ} \mathrm{C}$. Total mRNA was subsequently extracted with TRIzol ${ }^{\circledR}$ reagent (Invitrogen; Thermo Fisher Scientific, Inc.). Complementary (c)DNA was generated using a reverse transcription kit reagent kit (Promega Corporation). The mixture was incubated at $42^{\circ} \mathrm{C}$ for $10 \mathrm{~min}$. The resultant cDNA was then amplified using primers specific for P-gp (forward primer, 5'-TGACCC GCACTTCAGCTACAT-3'; and reverse primer, 5'-ACTGGG CTTCCCGATGATGTA-3'). As an internal control, GAPDH expression was detected (forward primer, 5'-TGACTTCAA CAGCGACACCCA-3' and reverse primer, 5'-CACCCTGTT GCTGTAGCCAA-3'). The PCR conditions were as follows: $94^{\circ} \mathrm{C}$ for $5 \mathrm{~min} ; 20$ cycles at $94^{\circ} \mathrm{C}$ for $60 \mathrm{sec}, 60^{\circ} \mathrm{C}$ for $30 \mathrm{sec}$ and $72^{\circ} \mathrm{C}$ for $60 \mathrm{sec}$; and $94^{\circ} \mathrm{C}$ for $5 \mathrm{~min}$. The PCR products were analyzed by electrophoresis on a $1.5 \%$ agarose gel and stained using ethidium bromide, then quantified using the ChemiImager 400 software (ProteinSimple). Experiments were conducted in triplicate and normalized to the expression of GAPDH.

Western blot analysis. Briefly, A549/T cells $\left(3 \times 10^{5}\right)$ were incubated with different concentrations of FKA $(0,2.5,5$, 10 and $30 \mu \mathrm{M}$ ) for $24 \mathrm{~h}$. Cell lysates were prepared using radioimmunoprecipitation assay lysis buffer according to the manufacturer's protocol (Beyotime Institute of Biotechnology, Inc.). Total protein was quantified using the BCA protein assay (Beyotime Institute of Biotechnology, Inc.). Samples containing equal amounts of protein $(50 \mu \mathrm{g})$ from the lysates were separated using 8 and 12\% SDS-PAGE and transferred to polyvinylidene difluoride membranes (EMD Millipore; Merck $\mathrm{KGaA}$ ). The blot was incubated with $5 \%$ skimmed milk for $1 \mathrm{~h}$ at room temperature. Next, the membrane was probed with monoclonal rabbit anti-human antibodies against P-gp, Akt and a polyclonal rabbit anti-human antibody against p-Akt (Ser 473) (all 1:1,000) overnight at $4^{\circ} \mathrm{C}$. Following washes with TBS/Tween-20 buffer, the membranes were incubated with either the HRP-labelled goat anti-rabbit secondary antibody $(1: 10,000)$ or the HRP-labelled goat anti-mouse secondary antibody $(1: 10,000)$ for $2 \mathrm{~h}$ at room temperature. GAPDH served as a protein loading control. For poly (ADP-ribose) polymerase (PARP) expression detection, the western blot 
method used is aforementioned however monoclonal rabbit anti-human PARP (cat. no. 46D11; 1:1,000) was used. $\beta$-actin served as a protein loading control. The ECL detection system (GE Healthcare Life Sciences) was used to detect the signal. Protein levels were quantified using densitometry using ImageJ v1.6 softwate (National Institutes of Health).

Inhibition or activation of PI3K/Akt signaling. The PI3K inhibitor LY294002 and the PI3K-specific agonist IGF-1 were used to suppress or activate the PI3K/Akt signaling pathway, respectively, in A549/T cells. Cells ( $1 \times 10^{4}$ cells/well) were incubated with the following: DMSO; $30 \mu \mathrm{M}$ FKA for $24 \mathrm{~h}$; LY294002 (10 $\mu \mathrm{M})$ for $1 \mathrm{~h}$; IGF-1 (12.5 nM) (15) for $1 \mathrm{~h} ; 30 \mu \mathrm{M}$ FKA for $24 \mathrm{~h}$, followed by LY294002 for $1 \mathrm{~h}$; or $30 \mu \mathrm{M}$ FKA for $24 \mathrm{~h}$, followed by IGF-1 for $1 \mathrm{~h}$. The protein expression levels of p-Akt (Ser 473) and P-gp were measured by western blot analysis. Each experiment was conducted in triplicates to determine the means and standard deviations (SDs).

Statistical analyses. The data are presented as the mean \pm SD of $\geq 3$ independent experiments and analyzed by GraphPad Prism 8 (GraphPad Software, Inc.). Comparisons of cell viability of human PTX-resistant A549/T cells and parental A549 cells following PTX or FKA treatment were evaluated by one-way analysis of variance (ANOVA) with Tukey's post-hoc test. Other multiple group comparisons were performed with one-way ANOVA, followed by Dunnett's multiple comparison test. $\mathrm{P}<0.05$ was considered to indicate a statistically significant difference.

\section{Results}

FKA significantly inhibits A549/T cell viability. As shown in Fig. 1A, PTX dose-dependently inhibited cell proliferation in A549 cells, with an $\mathrm{IC}_{50}$ value of $0.3 \mu \mathrm{M}$. However, the cell viability of PTX-resistant A549/T cells was $79 \%$ following treatment with $30 \mu \mathrm{M}$ PTX, and the $\mathrm{IC}_{50}$ was $34.64 \mu \mathrm{M}$. As shown in Fig. 1B, A549/T cells were sensitive to FKA, with a marginally decreased $\mathrm{IC}_{50}$ value of $\sim 21 \mu \mathrm{M}$ compared with $\sim 26 \mu \mathrm{M}$ in A549 cells. FKA at increasing concentrations of $2.5,5,10,20$ and $30 \mu \mathrm{M}$ resulted in decreased cell viability in a dose-dependent manner, inhibiting A549/T cell growth by $\sim 6.2,11.4,25.0,28.3$ and $59.4 \%$, while inhibiting A549 cell growth by $\sim 7.3,20.7,28.3,30.5$ and $56.8 \%$, respectively (Fig. 1B). In addition, FKA at $30 \mu \mathrm{M}$ exhibited almost no toxic effects on normal human hepatic epithelial THLE-3 cells (Fig. 1C). Moreover, morphological analysis revealed that cell shrinkage was observed following FKA treatment in A549/T cells, and cell shrinkage became more noticeable as the time and dose of FKA increased, suggesting that apoptosis was induced by FKA (Fig. 1D). The above data demonstrated that FKA was capable of inhibiting A549/T cell proliferation.

FKA induces apoptosis in A549/T cells. Flow cytometry was used to analyze apoptosis in A549/T cells treated with FKA. The results revealed that FKA caused a markedly dose-dependent increase in the proportion of apoptotic cells at $24 \mathrm{~h}$, with $\sim 9.2,17.9$ and $21.4 \%$ early and late apoptotic cells following treatment with 5, 10 and $30 \mu \mathrm{M}$ FKA, respectively (Fig. 2A). In addition, increased cleavage of PARP, a hallmark of apoptosis, was observed in A549/T cells exposed to $30 \mu \mathrm{M}$ FKA, (Fig. 2B). The nucleic morphological changes associated with apoptosis were assessed by staining nuclear DNA with DAPI. FKA treatment $(30 \mu \mathrm{M})$ at $48 \mathrm{~h}$ resulted in a marked increase in the number of apoptotic cells (indicated using arrows) with condensed and fragmented DNA (Fig. 2Ca) compared with A549/T cells treated with $30 \mu \mathrm{M}$ FKA for $24 \mathrm{~h}$ (Fig. 2Cb). Together, these results suggest that FKA induced apoptosis in A549/T cells.

FKA inhibits the protein expression of P-gp. RT-semi quantitative PCR and western blot analysis were performed to evaluate the effects of FKA on P-gp expression at the mRNA and protein level. The results demonstrated that the mRNA expression of P-gp slightly decreased to 90 and $80 \%$ compared with the control cells, following treatment with 3 and $30 \mu \mathrm{M}$ FKA, respectively (Fig. 3). However, the differences were not statistically significant. The results from the western blot analysis revealed that P-gp was not expressed in A549 cells but it was highly expressed in A549/T cells $(\mathrm{P}<0.01$; Fig. 4A). Subsequently, the protein levels of P-gp in A549/T cells were measured in response to various concentration of FKA. The expression of P-gp was significantly decreased, $\sim 3.0$-fold, following treatment with $30 \mu \mathrm{M}$ FKA for $24 \mathrm{~h}$ (Fig. 4B). Subsequently, the changes in P-gp expression with respect to treatment duration were investigated. As indicated in Fig. 4C, the level of P-gp expression decreased from 16 to $24 \mathrm{~h}$ ( 2.5-fold) following treatment with $30 \mu \mathrm{M}$ FKA. Thus, treatment with FKA decreased the protein expression of P-gp in A549/T cells.

FKA downregulates $P$-gp expression via inhibition of the PI3K/Akt signaling pathway. The involvement of PI3K/Akt signaling pathway in P-gp-mediated multidrug resistance has been reported (16). High protein expression of P-gp, Akt and p-Akt (Ser 473) was detected in A549/T cells. FKA downregulated the protein expression of P-gp, Akt and p-Akt (Ser 473). Notably, the levels of P-gp, Akt and p-Akt (Ser 473) were significantly decreased following treatment with $30 \mu \mathrm{M}$ FKA, as compared with the control group $(\mathrm{P}<0.05 ;$ Fig. 5). To confirm whether the suppression or activation of the PI3K/Akt pathway influenced the levels of P-gp, the effect of the PI3K inhibitor LY294002 and the PI3K agonist IGF-1 on P-gp and PI3K/Akt signaling was investigated. The expression of p-Akt (Ser 473) was decreased following treatment with LY294002 for $1 \mathrm{~h}$ compared with the untreated control $(\mathrm{P}<0.01$; Fig. $6 \mathrm{~A}$ and $\mathrm{B})$. A549/T cells treated with $30 \mu \mathrm{M}$ FKA for $24 \mathrm{~h}$ exhibited decreased expression of P-gp and p-Akt (Ser 473). In addition, the combined treatment of FKA and LY294002 (pretreatment with $30 \mu \mathrm{M}$ FKA for $24 \mathrm{~h}$, followed by treatment with $10 \mu \mathrm{M}$ LY294002 for $1 \mathrm{~h}$ ) exerted additive inhibitory effects on P-gp and p-Akt (Ser 473) expression. As illustrated in Fig. 6B, the expression levels of P-gp and p-Akt (Ser 473) were not influenced by PI3K agonist IGF-1 but inhibited by $30 \mu \mathrm{M}$ FKA. The combined treatment of FKA and IGF-1 (pretreatment with $30 \mu \mathrm{M}$ FKA for $24 \mathrm{~h}$, followed by treatment with IGF-1 for $1 \mathrm{~h}$ ) also inhibited the expression of p-Akt (Ser 473). Thus, $30 \mu \mathrm{M}$ FKA could reverse IGF-1-induced activation of the PI3K/Akt signaling pathway. Overall, FKA was demonstrated to inhibit P-gp expression via the PI3K/Akt signaling pathway. 
A

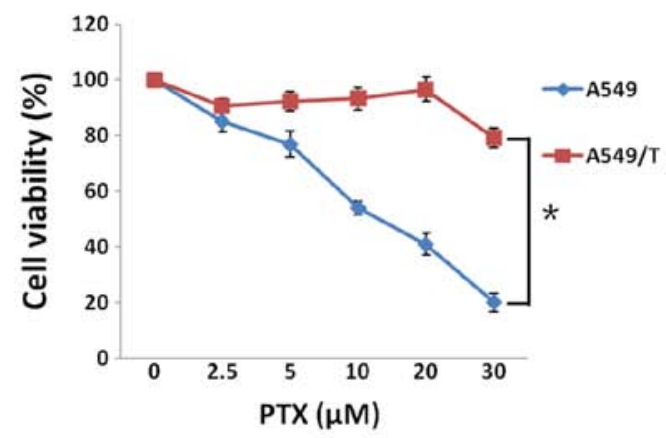

C

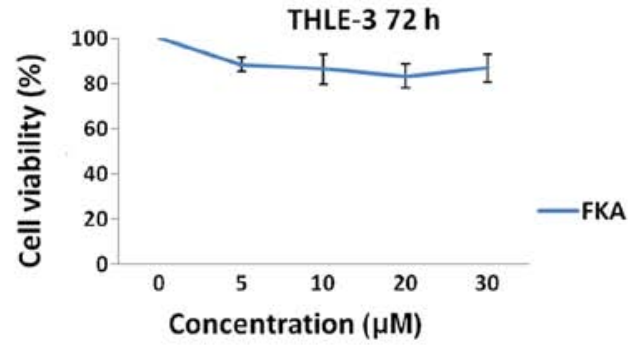

B

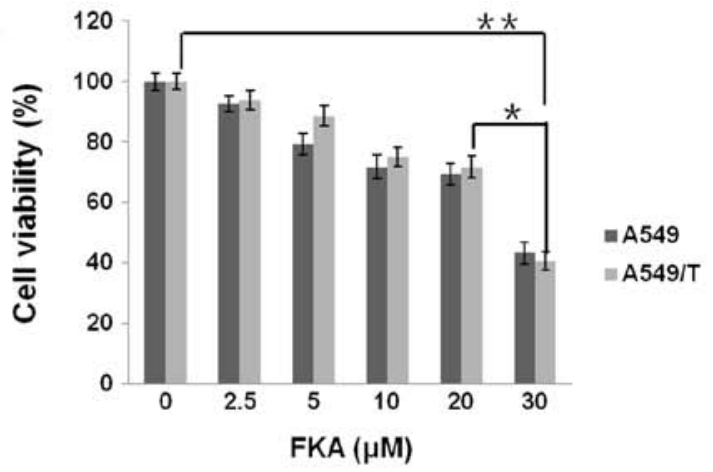

D

FKA $(\mu \mathrm{M})$
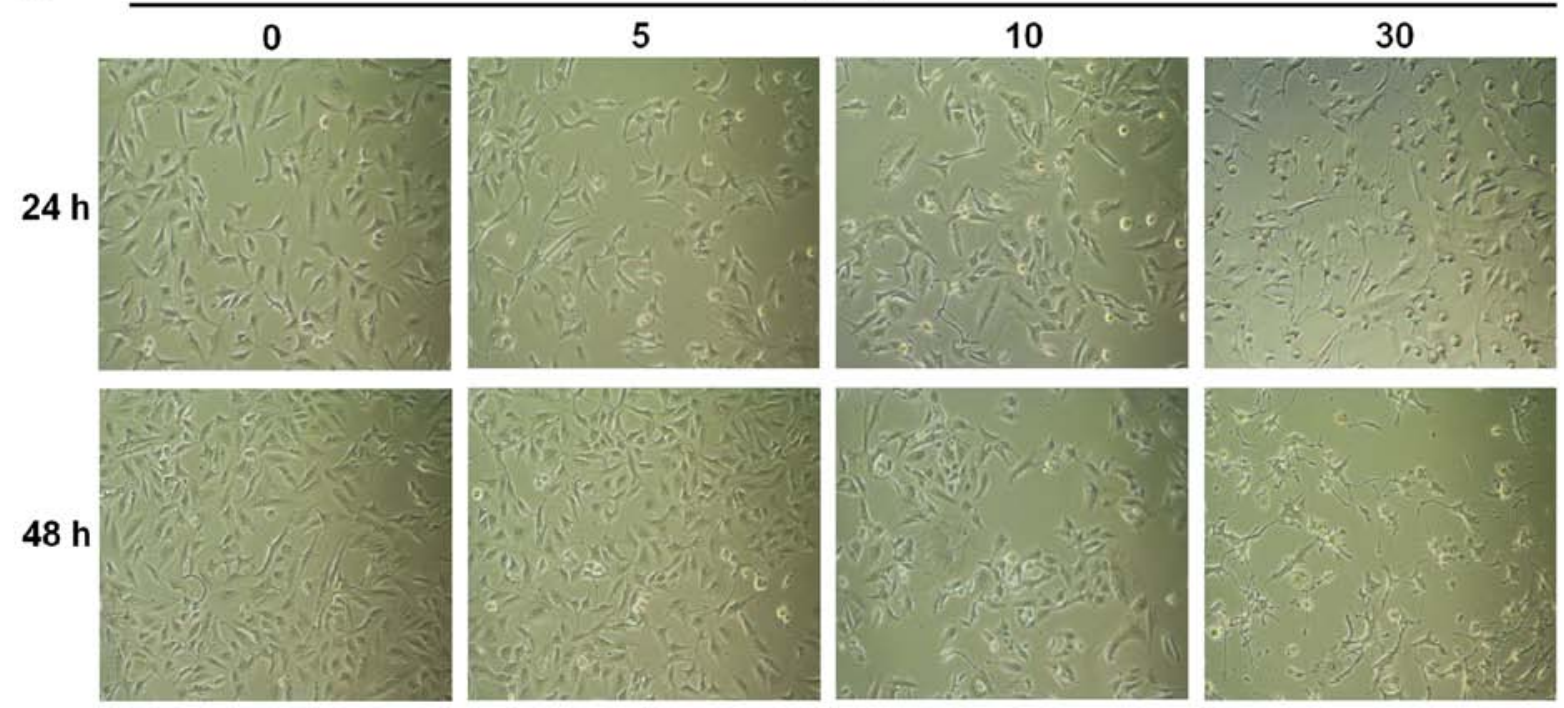

Figure 1. Effect of FKA on the viability of PTX-resistant A549 cells and normal human hepatic epithelial cells. (A) The in vitro effect of PTX on established human PTX-resistant A549/T and parental A549 cells. "P<0.05 vs. $30 \mu \mathrm{M}$ FKA treated A549/T cells. (B) Cell viability of A549 cells and A549/T cells following treatment with FKA for $48 \mathrm{~h}$, as determined by MTT assay. ${ }^{*} \mathrm{P}<0.05$ vs. $20 \mu \mathrm{M}$ FKA. ${ }^{* *} \mathrm{P}<0.01$ vs. $0 \mu \mathrm{M}$ FKA. (C) The effect of FKA on the viability of THLE-3 cells. (D) Morphological changes in A549/T cells following 48 h-treatment with $0,5,10$ and $30 \mu \mathrm{M}$ FKA. Data are presented as the mean \pm standard deviation of 3 independent experiments. FKA, flavokawain A; PTX, paclitaxel.

\section{Discussion}

Drug resistance is the main obstacle in cancer chemotherapy and results in poor therapeutic outcome (17). P-gp overexpression is one of the main mechanisms underlying drug resistance. Inhibiting the expression or function of P-gp is a key step towards improved treatment of patients with cancer. Inhibitors of the drug-efflux pump have been reported as effective in increasing the sensitivity to anticancer drugs (18). However, no potential modulators are currently licensed for clinical application, due to the associated toxicities or unacceptable side effects.

Chalcones and their derivatives have great advantages in overcoming chemotherapeutic drug resistance by inhibiting the protein expression or functions of ATP-binding cassette $(\mathrm{ABC})$ transporters, including P-gp and multidrug resistance (MDR)-associated protein 1 (MRP1) (19). 2'-Hydroxy-2,4,6'-trimethoxychalcone was shown to significantly inhibit the protein expression of P-gp in MES-SA/DX5 cells and overcome P-gp-mediated MDR in drug-resistant uterine sarcoma cells (20). Komoto et al (21) found that the chalcone licochalcone A decreased the protein expression of P-gp in BT20 breast cancer cells. The present study demonstrated that FKA did not block the efflux of Rh-123 out of cells (data not shown), which demonstrated that FKA had no influence on the efflux function of $A B C$ transporters. Furthermore, the mRNA expression of P-gp was unaffected following treatment with $30 \mu \mathrm{M}$ FKA. Conversely, the protein level of P-gp was significantly inhibited by $30 \mu \mathrm{M}$ FKA. In 
A $\operatorname{FKA}(\mu \mathrm{M})$

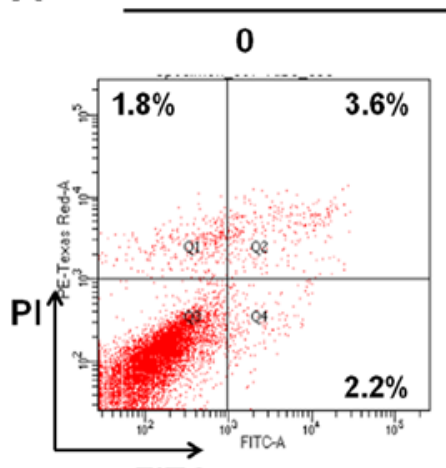

FITC

B
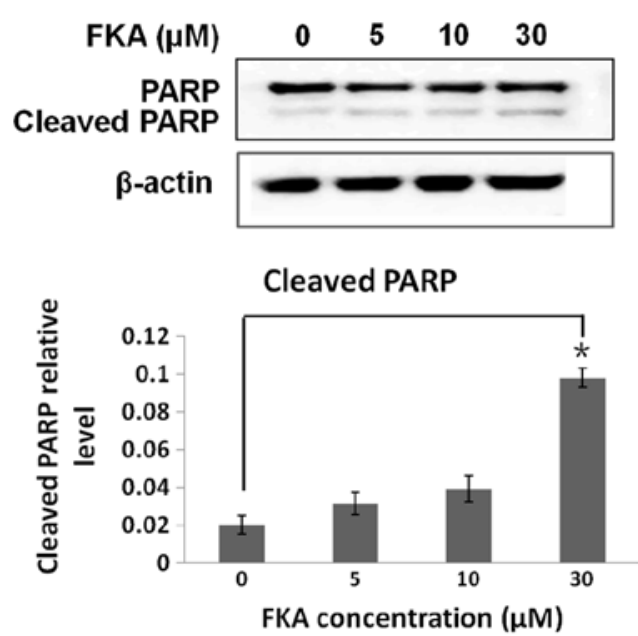

C $\operatorname{FKA}(\mu \mathrm{M})$

a

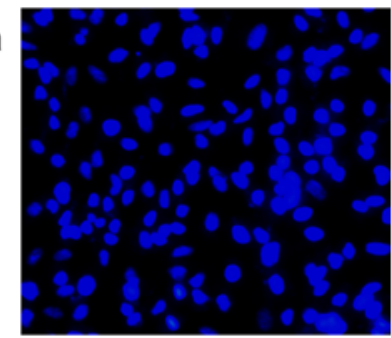

b

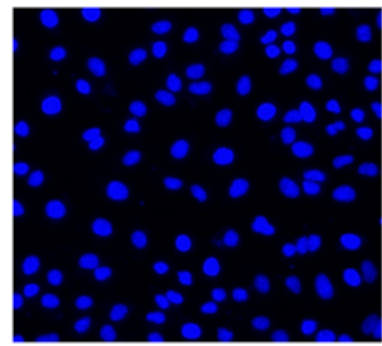

30
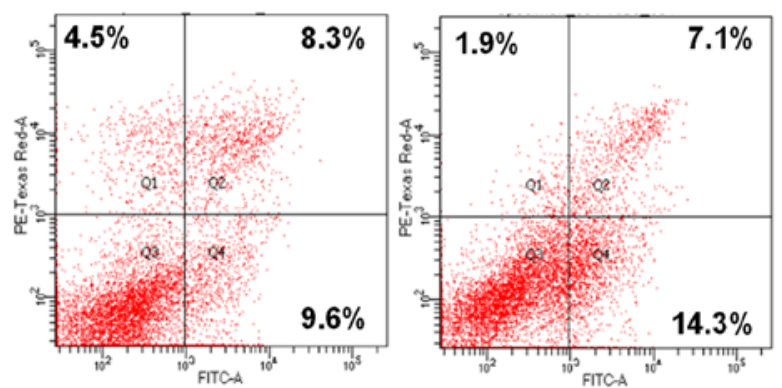

30
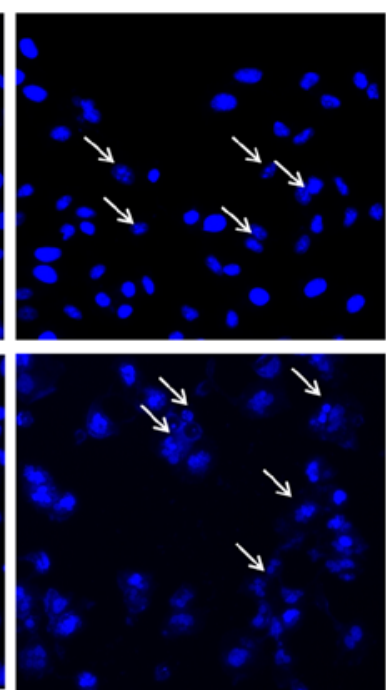

Figure 2. Effect of FKA on cell apoptosis in resistant A549/T cells. (A) FKA-induced cell apoptosis was detected by Annexin V/PI staining and flow cytometry analysis. (B) The expression of PARP in cells treated with FKA at various concentrations was examined by western blot analysis. $\beta$-actin served as the loading control. "P<0.05 vs. treated with $0 \mu \mathrm{M}$ FKA. (C) Apoptosis in A549/T cells was visualized using nuclear DAPI staining. Cells were exposed for 24 or $48 \mathrm{~h}$ at $37^{\circ} \mathrm{C}$, following the indicated treatments, prior to staining with DAPI for $30 \mathrm{~min}$. Arrow pointing to apoptotic cells. FKA, flavokawain A; PARP, poly (ADP-ribose) polymerase.

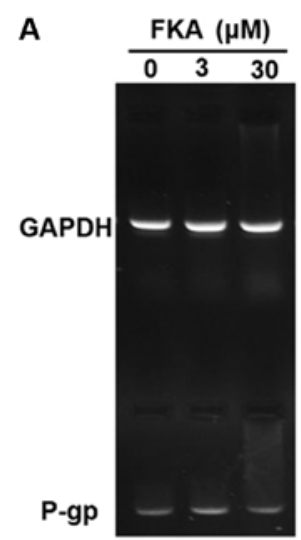

B

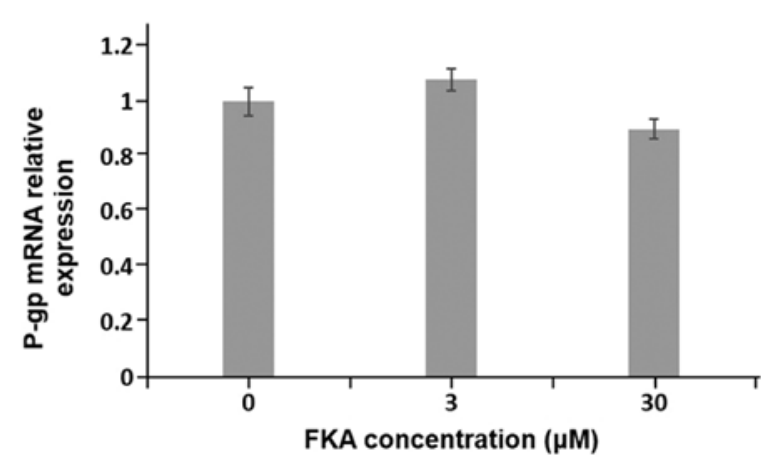

Figure 3. FKA inhibits P-gp mRNA expression. (A) Image of agarose ethidium bromide gel and (B) P-gp mRNA expression in A549/T cells treated with 0, 3 and $30 \mu \mathrm{M}$ FKA. FKA, flavokawain A; P-gp, permeability-glycoprotein.

summary, to the best of our knowledge, the present study is the first to report that FKA decreased the viability of A549/T cells by inhibiting the protein expression of P-gp.

The PI3K/Akt pathway is a commonly activated signaling pathway in cancer, which plays an important role in inhibiting cancer cell apoptosis and promoting cancer cell proliferation, invasion and angiogenesis (22). As the central node of the PI3K/Akt signaling cascade, Akt activates multiple oncogenic signaling pathways to promote cancer, and Akt hyperactivation has been associated with poor differentiation and worse 
A

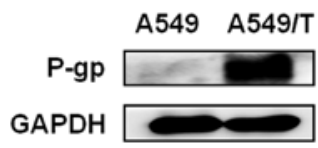

B

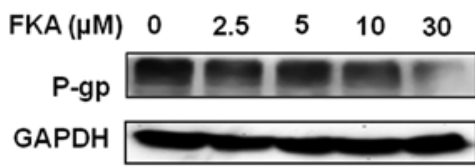

C

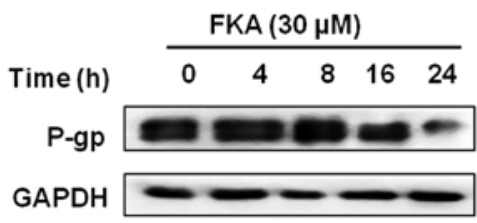

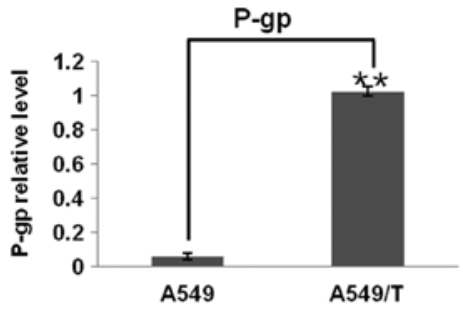
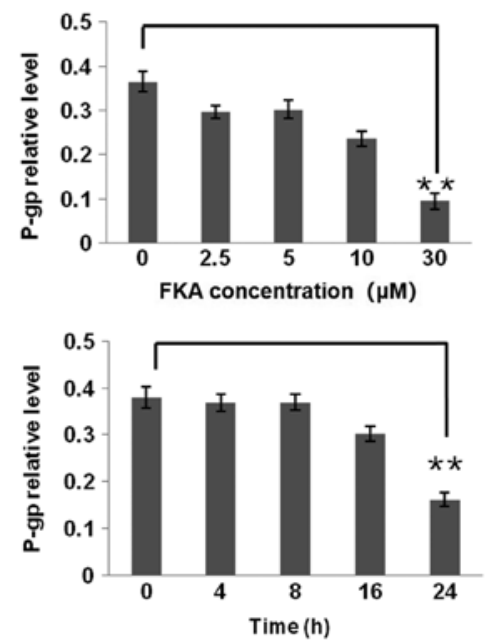

Figure 4. FKA inhibits P-gp protein expression. (A) Western blot analysis of P-gp expression in A549 and A549/T cells. The expression of P-gp in A549/T cells treated with (B) FKA for $24 \mathrm{~h}$ at various concentrations and (C) $30 \mu \mathrm{M}$ FKA at various times. ${ }^{* *} \mathrm{P}<0.01$. FKA, flavokawain A; P-gp, permeability-glycoprotein.

A

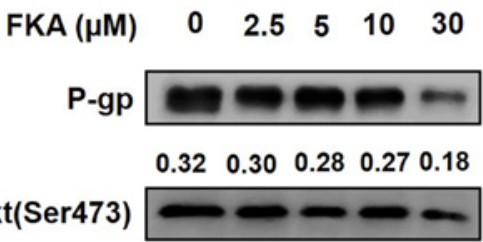

Akt

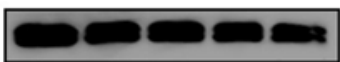

GAPDH
B
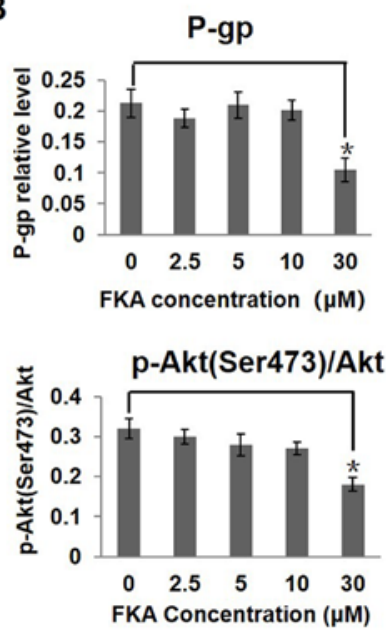

Figure 5. FKA inhibits the PI3K/Akt signaling pathway in A549/T cells. Western blot analysis of the (A) protein expression levels of P-gp, Akt and p-Akt (Ser 473) in A549/T cells treated with various concentrations of FKA for $24 \mathrm{~h}$. GAPDH served as an internal control for P-gp and total Akt was used for p-Akt, The ratios of p-Akt (Ser 473) to Akt after treated with 0, 2.5, 5, 10 and $30 \mu \mathrm{M}$ FKA were $0.32,0.3,0.28,0.27,0.18$ respectively. (B) The relative protein level of P-gp, Akt and p-Akt (Ser 473) was quantified using densitometry. ${ }^{*} \mathrm{P}<0.05$ vs. $0 \mu \mathrm{M}$ FKA. FKA, flavokawain A; P-gp, permeability-glycoprotein, p-, phosphorylated.

prognosis (23). Akt also regulates the expression of the MDRI gene, while P-gp is one of the downstream factors of the PI3K/Akt pathway (24). Increased Akt phosphorylation has been reported to be associated with chemotherapeutic resistance (25). However, the association between the inhibition of P-gp expression and the PI3K/Akt pathway by FKA is still unclear. In the present study, the effect of FKA on P-gp expression via the PI3K/Akt pathway was investigated. PTX-resistant A549/T cells displayed high expression levels of p-Akt and $\mathrm{P}$-gp, which represented high PI3K/Akt activity, as well as an association between PI3K signaling and the resistant phenotype. Following treatment with $30 \mu \mathrm{M}$ FKA, the expression levels of P-gp, Akt and p-Akt (Ser 473) decreased significantly. In addition, it was found that LY294002 and IGF-1 promoted and inhibited Akt phosphorylation, respectively. These results indicated that FKA inhibited P-gp expression by inhibiting the PI3K/Akt pathway.

Numerous small molecule Akt inhibitors have been developed and tested in preclinical or clinical models. Ipatasertib, a novel selective ATP competitive small-molecule inhibitor of 
A

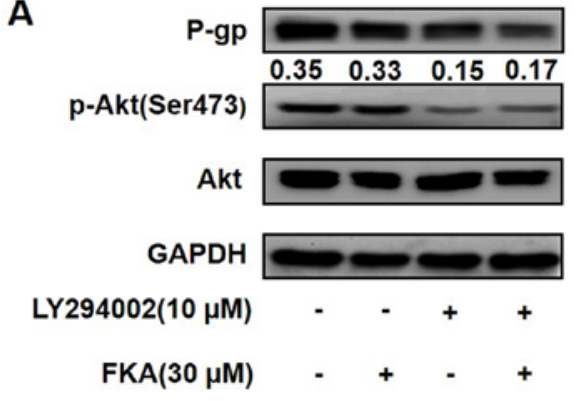

C
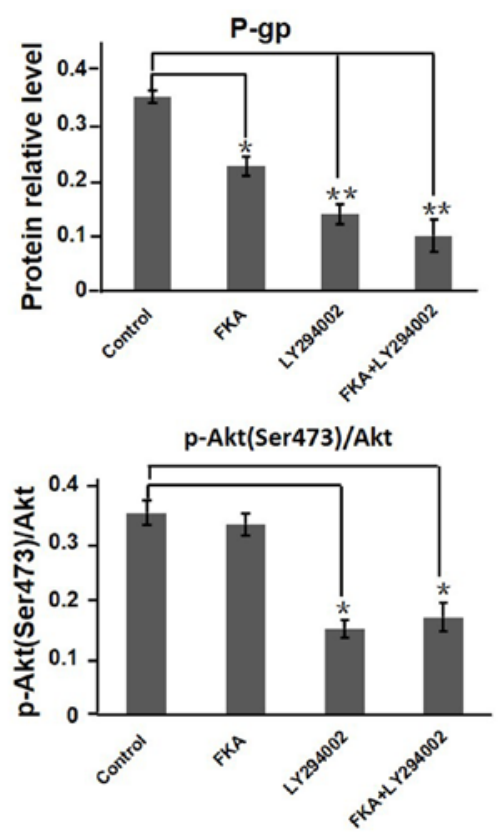

B

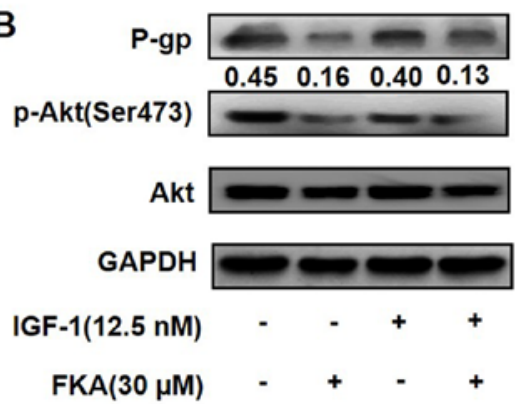

D
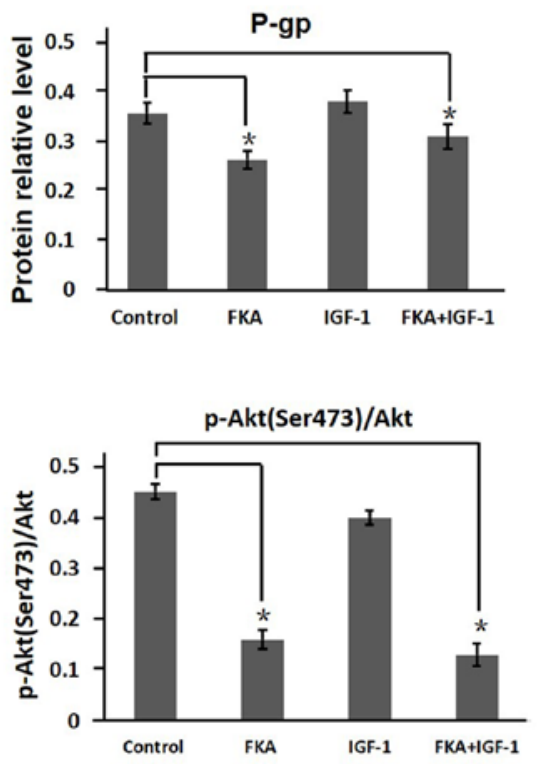

Figure 6. FKA downregulates P-gp expression via inhibition of the PI3K/Akt signaling pathway. A549/T cells were either untreated or treated with (A) FKA, LY294002 or co-treated with FKA and LY294002 or (B) FKA, IGF-1 or co-treated with FKA and IGF-1 using western blot analysis. GAPDH served as the internal control for P-GP and total AKT served as an internal control for p-AKT. The ratios of p-Akt (Ser 473) to Akt treated with control, FKA, LY294002 or FKA combined with LY294002 were $0.35,0.33,0.15,0.17$ respectively. The ratios of p-Akt (Ser 473) to Akt treated with control, FKA, IGF-1 or FKA combined with IGF-1 were 0.45, 0.16, 0.4, 0.13 respectively. The relative level of P-gp, Akt and p-Akt (Ser 473) after treatment with (C) FKA, LY294002 or FKA combined with LY294002 and (D) FKA, IGF-1 or FKA combined with IGF-1 treatment. ${ }^{*} \mathrm{P}<0.05 .{ }^{* *} \mathrm{P}<0.01$. FKA, flavokawain A; P-gp, permeability-glycoprotein, p-, phosphorylated; IGF-1, insulin-like factor-1.

Akt, preferentially targets active p-Akt and exerts anti-tumor activity (26). LY294002, a flavonoid-derived PI3K/Akt inhibitor, inhibits PI3K by competing with ATP for binding to the PI3K active site (27). LY294002 also inhibits Akt phosphorylation (28). Furthermore, it was reported that LY294002 had inhibitory effects on $\mathrm{ABC}$ transporters, including breast cancer resistance protein (BCRP), MRP1 and P-gp. LY294002 competitively inhibited the transport activity of BCRP, while exerting inhibitory effects on MRP1 function via competitive inhibition of substrate transport and modulation of expression (29). LY294002 also antagonized the transport activity of P-gp without influencing its expression (29). Since FKA belongs to flavonoid/isoflavonoid compounds, its chemical structure is similar to that of LY294002. The present study demonstrated the inhibition of P-gp protein expression, rather than its pumping function, by FKA. The inhibitory effect of FKA on BCRP and MRP1 requires further investigation.

The kinase function of Akt is activated following the phosphorylation of two residues, threonine 308 ( Thr 308) and serine 473 (Ser 473). It was reported that FKA downregulates
Akt activation by suppressing Akt phosphorylation in HER2-overexpressing breast cancer cells (14). In the present study, FKA suppressed Akt activation by decreasing p-Akt (Ser 473) expression level. The Akt (pan) (C67E7) monoclonal anitbody (cat. no. 4691; Cell Signaling Technology, Inc.) detects endogenous levels of total (both phosphorylated and non-phosphorylated) Akt1, Akt2 and Akt3 protein. The target undergoes a wide range of post-translational modifications (PTMs). These PTMs can lead to a slight shift in signal. Each Akt isoform can have a unique expression pattern depending on the specific treatment and specific cells. The existing two bands of Akt (in Fig. 5A and Fig. 6) are close in size to $60 \mathrm{kDa}$ is common in A549 cells. The same double band pattern was also observed in A549 cells in other publications detecting total Akt $(30,31)$.

A previous report claimed that kava extracts may cause hepatotoxicity (32). Interestingly, it was reported that liver toxicity cases occurred in the South Pacific region only, and this may be due to the tropical humidity and temperature as the kava plants may have been contaminated by mould 
hepatotoxins instead (33). A previous study also confirmed that kava alone did not affect mouse development and induced no signs of hepatotoxicity (34). In order to detect whether FKA has hepatotoxicity, the effect of FKA on human normal liver cells was investigated. The result demonstrated that FKA exerted no obvious hepatotoxicity to normal liver epithelial cells. Overall, there is a need to determine the acute and subchronic toxicity of FKA in vivo.

The effect of FKA on the expression of other ABC transporters such as MRP1 and BCRP has not been studied. Thus, further investigation is required in order to fully understand the mechanism by which FKA inhibits the function of ABC transporters and to determine the signaling pathway that inhibits P-gp expression. In addition, the inhibitory activity of FKA alone or combined with chemotherapy drugs in resistant tumor cells requires investigation in future in vivo studies.

In summary, the present study demonstrated the capacity of FKA to decrease the viability in PTX-resistance cells and inhibit P-gp expression. Furthermore, FKA inhibits the protein expression of P-gp via inhibition of the PI3K/Akt pathway. The findings of the present study may provide a foundation for the development of better strategies for reversing chemotherapy resistance.

\section{Acknowledgements}

The authors would like to thank Dr Wen Jiang for flow cytometry data analysis and Dr Lu Zhang for providing the cells (both Central Research Laboratory at the Second Hospital of Shandong University, Shandong, China).

\section{Funding}

The present study was funded by the Shandong Natural Science Foundation (grant no. ZR2017BH014), the Shandong Key Research and Development Program (grant nos. 2018GSF118010 and 2018GSF118075) and the Shandong Province Medical and Health Technology Development Plan (grant no. 2016WS0334).

\section{Availability of data and materials}

The datasets used and/or analyzed during the present study are available from the corresponding author on reasonable request.

\section{Authors' contributions}

JL and RW designed the study. JL, MY, YL, JW and XT performed the experiments. JL and RW contributed new reagents and analytic tools. LeZ WJ and LuZ analyzed the data. JL wrote the paper. JL and RW revised the paper.

\section{Ethics approval and consent to participate}

Not applicable.

\section{Patient consent for publication}

Not applicable.

\section{Competing interests}

The authors declare that they have no competing interests.

\section{References}

1. Bray F, Ferlay J, Soerjomataram I, Siegel RL, Torre LA and Jemal A: Global cancer statistics 2018: GLOBOCAN estimates of incidence and mortality worldwide for 36 cancers in 185 countries. CA Cancer J Clin 68: 394-424, 2018.

2. Chakravarty G, Mathur A, Mallade P, Gerlach S, Willis J, Datta A, Srivastav S, Abdel-Mageed AB and Mondal D: Nelfinavir targets multiple drug resistance mechanisms to increase the efficacy of doxorubicin in MCF-7/Dox breast cancer cells. Biochimie 124: 53-64, 2016.

3. Podolski-Renić A,BankovićJ,DinićJ,Ríos-LuciC, Fernandes MX, Ortega N, Kovačević-Grujičić N, Martín VS, Padrón JM and Pešić M: DTA0100, dual topoisomerase II and microtubule inhibitor, evades paclitaxel resistance in P-glycoprotein overexpressing cancer cells. Eur J Pharm Sci 105: 159-168, 2017.

4. Abraham J, Salama NN and Azab AK: The role of P-glycoprotein in drug resistance in multiple myeloma. Leuk Lymphoma 56: 26-33, 2015.

5. Joshi P, Vishwakarma RA and Bharate SB: Natural alkaloids as P-gp inhibitors for multidrug resistance reversal in cancer. Eur J Med Chem 138: 273-292, 2017.

6. Guo Q, Cao H, Qi X, Li H, Ye P, Wang Z, Wang D and Sun M: Research progress in reversal of tumor multi-drug resistance via natural products. Anticancer Agents Med Chem 17: 1466-1476, 2017.

7. Liu Y, Yue C, Li J, Wu J, Wang S, Sun D, Guo Y, Lin Z, Zhang D and Wang R: Enhancement of cisplatin cytotoxicity by retigeric acid $B$ involves blocking DNA repair and activating DR5 in prostate cancer cells. Oncol Lett 15: 2871-2880, 2018.

8. Cabral BLS, da Silva ACG, de Ávila RI, Cortez AP, Luzin RM, Lião LM, de Souza Gil E, Sanz G, Vaz BG, Sabino JR, et al: A novel chalcone derivative, LQFM064, induces breast cancer cells death via p53, p21, KIT and PDGFRA. Eur J Pharm Sci 107: 1-15, 2017.

9. Santos MB, Pinhanelli VC, Garcia MAR, Silva G, Baek SJ, França SC, Fachin AL, Marins $M$ and Regasini LO: Antiproliferative and pro-apoptotic activities of 2'-and 4'-aminochalcones against tumor canine cells. Eur J Med Chem 138: 884-889, 2017.

10. Lee DH, Jung Jung Y, Koh D, Lim Y, Lee YH and Shin SY: A synthetic chalcone, 2'-hydroxy-2,3,5'-trimethoxychalcone triggers unfolded protein response-mediated apoptosis in breast cancer cells. Cancer Lett 372: 1-9, 2016.

11. Jandial DD, Blair CA, Zhang S, Krill LS, Zhang YB and Zi X: Molecular targeted approaches to cancer therapy and prevention using chalcones. Curr Cancer Drug Targets 14: 181-200, 2014.

12. Abu N, Akhtar MN, Yeap SK, Lim KL, Ho WY, Zulfadli AJ, Omar AR, Sulaiman MR, Abdullah MP and Alitheen NB: Flavokawain A induces apoptosis in MCF-7 and MDA-MB231 and inhibits the metastatic process in vitro. PLoS One 9: e105244, 2014.

13. Abu N, Mohameda NE, Tangarajoo N, Yeap SK, Akhtar MN, Abdullah MP, Omar AR and Alitheen NB: In vitro toxicity and in vivo immunomodulatory effects of flavokawain A and flavokawain B in Balb/C mice. Nat Prod Commun 10: 1199-1202, 2015.

14. Jandial DD, Krill LS, Chen L, Wu C, Ke Y, Xie J, Hoang BH and $\mathrm{Zi} \mathrm{X}$ : Induction of G2M arrest by flavokawain $\mathrm{A}$, a kava chalcone, increases the responsiveness of HER2-overexpressing breast cancer cells to herceptin. Molecules 22: E462, 2017.

15. Zhang S, Kuang G, Zhao G, Wu X, Zhang C, Lei R, Xia T, Chen J, Wang Z, Ma R, et al: Involvement of the mitochondrial p53 pathway in PBDE-47-induced SH-SY5Y cells apoptosis andits underlying activation mechanism. Food Chem Toxicol 62: 699-706, 2013

16. Muthusamy G, Gunaseelan S and Prasad NR: Ferulic acid reverses P-glycoprotein-mediated multidrug resistance via inhibition of PI3K/Akt/NF-кB signaling pathway. J Nutr Biochem 63: 62-71, 2019.

17. Ma H, Cheng L, Hao K, Li Y, Song X, Zhou H and Jia L: Reversal effect of ST6GAL 1 on multidrug resistancein human leukemia by regulating the PI3K/Akt pathway and the expression of P-gp and MRP1. PLoS One 9: e85113, 2014.

18. Calatozzolo C, Gelati M, Ciusani E, Sciacca FL, Pollo B, Cajola L, Marras C, Silvani A, Vitellaro-Zuccarello L, Croci D, et al: Expression of drug resistance proteins Pgp, MRP1, MRP3, MRP5 and GST-pi in human glioma. J Neurooncol 74: 113-121, 2005. 
19. Lindamulage IK, Vu HY, Karthikeyan C, Knockleby J, Lee YF, Trivedi $\mathrm{P}$ and Lee $\mathrm{H}$ : Novel quinolone chalcones targeting colchicine-binding pocket kill multidrug-resistant cancer cells by inhibiting tubulin activity and MRP1 function. Sci Rep 7: 10298, 2017.

20. Shin SY, Lee MS, Lee DH, Lee DH, Koh D and Lee YH: The synthetic compound 2'-hydroxy-2,4,6'-trimethoxychalcone overcomes P-glycoprotein-mediated multi-drug resistance in drug-resistant uterine sarcoma MES-SA/DX5 cells. J Korean Soc Appl Bi 58: 105-109, 2015.

21. Komoto TT, Bernardes TM, Mesquita TB, Bortolotto LFB, Silva G, Bitencourt TA, Baek SJ, Marins M and Fachin AL: Chalcones repressed the AURKA and MDR proteinsinvolved in metastasis and multiple drug resistance in breast cancer cell lines. Molecules 23: 2018, 2018.

22. Wang H, Jia XH, Chen JR, Wang JY and Li YJ: Osthole shows the potential to overcome P-glycoprotein-mediated multidrug resistance in human myelogenous leukemia K562/ADM cells by inhibiting the PI3K/Akt signaling pathway. Oncol Rep 35: 3659-3668, 2016.

23. Cao Z, Liao Q, Su M, Huang K, Jin J and Cao D: AKT and ERK dual inhibitors: The way forward? Cancer Lett 459: 30-40, 2019.

24. Han Z, Hong L, Han Y, Wu K, Han S, Shen H, Li C, Yao L, Qiao T and Fan D: Phospho Akt mediates multidrug resistance of gastric cancer cells through regulation of P-gp, Bcl-2 and Bax. J Exp Clin Cancer Res 26: 261-268, 2007.

25. Morishita N, Tsukahara H, Chayama K, Ishida T, Washio K, Miyamura T, Yamashita N, Oda M and Morishima T: Activation of Akt is associated with poor prognosis and chemotherapeutic resistance in pediatric B-precursor acute lymphoblastic leukemia. Pediatr Blood Cancer 59: 83-89, 2012.

26. Saura C, Roda D, Roselló S, Oliveira M, Macarulla T, Pérez-Fidalgo JA, Morales-Barrera R, Sanchis-García JM, Musib L, Budha N, et al: A first-in-human phase I study of the ATP-competitive AKT inhibitor ipatasertib demonstrates robust and safe targeting of AKT in patients with solid tumors. Cancer Discov 7: 102-113, 2017.
27. Toledo LM, Lydon NB and Elbaum D: The structure-based design of ATP-site directed protein kinase inhibitors. Curr Med Chem 6: 775-805, 1999

28. Ohnishi K, Yasumoto J, Takahashi A and Ohnishi T: LY294002, an inhibitor of PI-3K, enhances heat sensitivity independently of p53 status in human lung cancer cells. Int J Oncol 29: 249-253, 2006.

29. Imai Y, Yamagishi H, Ono Y and Ueda Y: Versatile inhibitory effects of the flavonoid-derived PI3K/Akt inhibitor, LY294002, on ATP-binding cassette transporters that characterize stem cells. Clin Transl Med 1: 24, 2012.

30. Cao P, Liu B, Du F, Li D, Wang Y, Yan X, Li X and Li Y: Scutellarin suppresses proliferation and promotes apoptosis in A549 lung adenocarcinoma cells via AKT/mTOR/4EBP1 and STAT3 pathways. Thorac Cancer 10: 492-500, 2019.

31. Jiang W, Chen Y, Song X, Shao Y, Ning Z and Gu W: Pim-1 inhibitor SMI-4a suppresses tumor growth in non-small cell lung cancer via PI3K/AKT/mTOR pathway. Onco Targets Ther 12: 3043-3050, 2019.

32. Teschke R: Kava hepatotoxicity-a clinical review. Ann Hepatol 9: 251-265, 2010.

33. Teschke R, Qiu SX and Lebot V: Herbal hepatotoxicity by kava: Update on pipermethystine, flavokavain B, and mould hepatotoxins as primarily assumed culprits. Dig Liver Dis 43: 676-681, 2011.

34. Narayanapillai SC, Leitzman P, O'Sullivan MG and Xing C: Flavokawains a and B in kava, not dihydromethysticin, potentiate acetaminophen-induced hepatotoxicity in C57BL/6 mice. Chem Res Toxicol 27: 1871-1876, 2014.

This work is licensed under a Creative Commons Attribution-NonCommercial-NoDerivatives 4.0 International (CC BY-NC-ND 4.0) License. 